\title{
Calderas volcánicas y su relación con recursos geotermales en el sur del Perú
}

\author{
Volcanic calderas and its relation to geothermal resources in southern Peru
}

\author{
Guillermo Nicanor Díaz Huaina ${ }^{1, a}$, Enrique Guadalupe Gómez 1,b
}

Recibido: 22/01/2021 - Aprobado: 19/04/2021 - Publicado: 18/06/2021

\section{RESUMEN}

El área de estudio comprende desde los $13.8^{\circ}$ hasta los $18.3^{\circ}$ de latitud sur del territorio peruano, abarca principalmente las regiones de Tacna, Moquegua, Arequipa y parte de Ayacucho, Apurímac y Puno. Geomorfológicamente abarca principalmente la cordillera Occidental y parte del Altiplano.

Con base en imágenes satelitales, información de geología regional y distribución de fuentes termales se determinó once (11) estructuras caldéricas de diversas dimensiones. La geometría de las estructuras en algunos casos se determina gracias a patrones geomorfológicos de ambiente volcánico.

Se determinó que en la zona de estudio, existe una amplia distribución de lavas y rocas piroclásticas recientes, las cuales enmascaran las estructuras caldéricas y por otro lado deja oculto diversos sistemas geotermales. En algunos casos se presenta manifestaciones geotermales en superficie, las cuales han salido mediante fallas recientes.

La distribución de manifestaciones geotermales coincide en muchos casos con los bordes de las estructuras caldéricas y también está controlada por sistemas estructurales, contactos geológicos, los cuales se intersectan con bordes de referidas calderas.

Por lo tanto, se concluye que en el sur del Perú existe un promisorio potencial de recursos geotérmicos, en algunos casos con manifestaciones visibles en superficie y otros ocultos por materiales volcánicos recientes.

Palabras clave: Cámara magmática; estructuras caldéricas; fallas; sistemas geotermales.

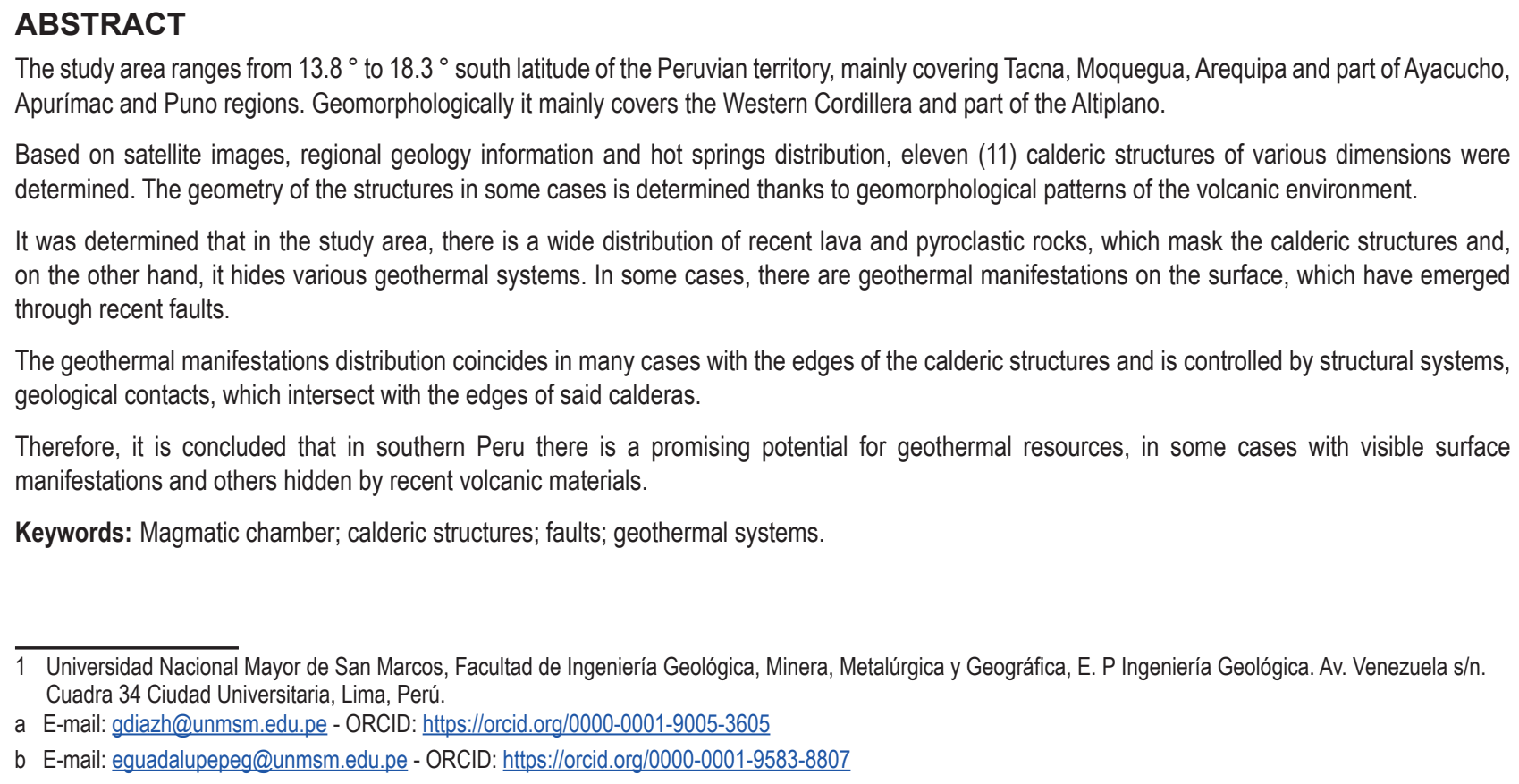

The study area ranges from $13.8^{\circ}$ to $18.3^{\circ}$ south latitude of the Peruvian territory, mainly covering Tacna, Moquegua, Arequipa and part of Ayacucho, Apurímac and Puno regions. Geomorphologically it mainly covers the Western Cordillera and part of the Altiplano.

Based on satellite images, regional geology information and hot springs distribution, eleven (11) calderic structures of various dimensions were determined. The geometry of the structures in some cases is determined thanks to geomorphological patterns of the volcanic environment.

It was determined that in the study area, there is a wide distribution of recent lava and pyroclastic rocks, which mask the calderic structures and, on the other hand, it hides various geothermal systems. In some cases, there are geothermal manifestations on the surface, which have emerged through recent faults.

The geothermal manifestations distribution coincides in many cases with the edges of the calderic structures and is controlled by structural systems, geological contacts, which intersect with the edges of said calderas.

Therefore, it is concluded that in southern Peru there is a promising potential for geothermal resources, in some cases with visible surface manifestations and others hidden by recent volcanic materials.

Keywords: Magmatic chamber; calderic structures; faults; geothermal systems.

\footnotetext{
1 Universidad Nacional Mayor de San Marcos, Facultad de Ingeniería Geológica, Minera, Metalúrgica y Geográfica, E. P Ingeniería Geológica. Av. Venezuela s/n. Cuadra 34 Ciudad Universitaria, Lima, Perú.

a E-mail: gdiazh@unmsm.edu.pe - ORCID: https://orcid.org/0000-0001-9005-3605

b E-mail: eguadalupepeg@unmsm.edu.pe- ORCID: https://orcid.org/0000-0001-9583-8807
} 


\section{INTRODUCCIÓN}

El Perú forma parte del denominado Círculo del Fuego del Pacífico que se caracteriza por la manifestación de sismos, la presencia de arcos volcánicos donde sobresalen volcanes como el denominado Cordillera del Barroso (Jenks, 1948), donde destacan algunos volcanes activos (Volcán Ubinas, Sabancaya) que indican la existencia de una alta termalidad asociada a la presencia cámaras magmáticas en profundidad. Esto configura al sur del Perú, en una zona promisoria para explotación geotérmica.
Los estudios iniciados en la Geotermia se remontan a los años 1978 cuando el Instituto Geológico Minero y Metalúrgico (INGEMMET) realiza un inventario a nivel nacional de la presencia de aguas termales a lo largo y ancho del Perú que permitió elaborar el Mapa de Regiones Geotermales en el Perú (figura 1).

Posteriormente, ELECTROPERU a partir de 1983 inicia los estudios de exploración geotérmica en la Región 5 denominada Eje Volcánico Sur (figura 2) caracterizada por la presencia de volcanes que conforman parte del

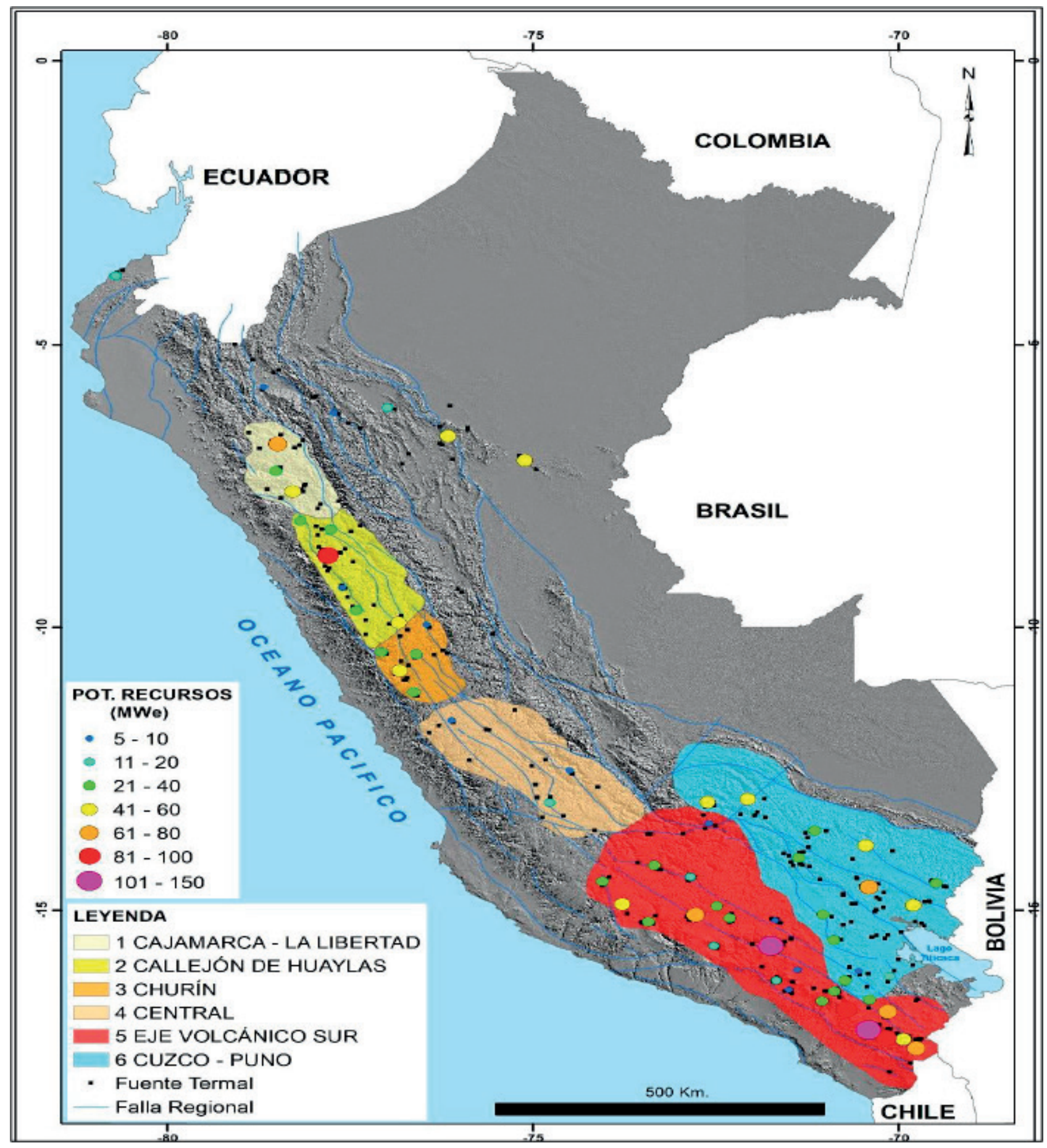

Figura 1. Mapa de regiones geotermales del Perú (Fuente: INGEMMET) 
arco volcánico, tomándose como referencia la ubicación de las fuentes termales con temperaturas promedio de $60{ }^{\circ} \mathrm{C}$, realizándose un muestreo geoquímico, con toma de muestras para ser analizado en laboratorio y con los resultados aplicar fórmulas de geotermometría y estimar la temperatura aproximada en profundidad y la toma de parámetros físicos como temperatura, conductividad eléctrica, $\mathrm{pH}$.

A la actualidad INGEMMET ha seguido realizando estudios en el Región 5, pero siempre con el criterio de localizar las aguas termales en un área determinada, revaluándose trabajos que ya realizó ELECTROPERU.

El presente artículo presenta otro criterio como evaluar el potencial geotérmico basado en la identificación de calderas volcánicas, asociado a la presencia de extensos depósitos de rocas volcánicas como las rocas piroclásticas que cubren grandes extensiones en el sur del Perú con relación a la Región 5, y que está asociados a la presencia de las aguas termales.

Se denomina una caldera a una estructura circular, con hundimiento del terreno, como resultado de la salida de material magmático (Lipman, 2000), especialmente del tipo explosivo proveniente de la existencia en profundidad de una cámara magmática, que da origen a las rocas piroclásticas y esta salida de este material puede ser días o semanas, y se ha llegado a estimar la salida de material de $2000 \mathrm{~km}$ cúbicos (Gregg et al., 2012).

\section{MÉTODOS}

El presente trabajo se realizó principalmente en gabinete, en la cual se da la recopilación de información bibliográfica, geología regional, análisis e interpretación de imágenes satelitales. Además, se empleó información de dataciones radiométricas, inventario de fuentes termales, afloramiento de depósitos piroclásticos y las estructuras circulares.

Con toda la información disponible, se procede a ordenar en capas y posteriormente se integra haciendo uso de un sistema de información geográfica, luego se hace el análisis tratando de encontrar patrones de distribución espacial de las diversas capas de información y finalmente se delimita las estructuras circulares que tengan mejor consistencia con todos los criterios establecidos previamente.

\subsection{Metodología propuesta para ubicar un yacimiento geotérmico}

La presencia de extensos depósitos de rocas piroclásticas (tobas) en el sur del Perú, que afloran en la denominada región 5 , ha conllevado a preguntarse por donde se emitieron estos productos que han sido denominada de acuerdo a la nomenclatura empleada en los cartografiados geológicos de los cuadrángulos del sur del Perú como Formación Huaylillas (Wilson \& García, 1962), Grupo Nazca (Noble et al., 1979), Formación Alpabamba (Guevara \& Dávila, 1983), Formación Sencca (Mendívil Echevarría, 1965) y otros depósitos de rocas como las formaciones Andamarca y Aniso (Guevara \& Dávila, 1983); que fueron asumidos

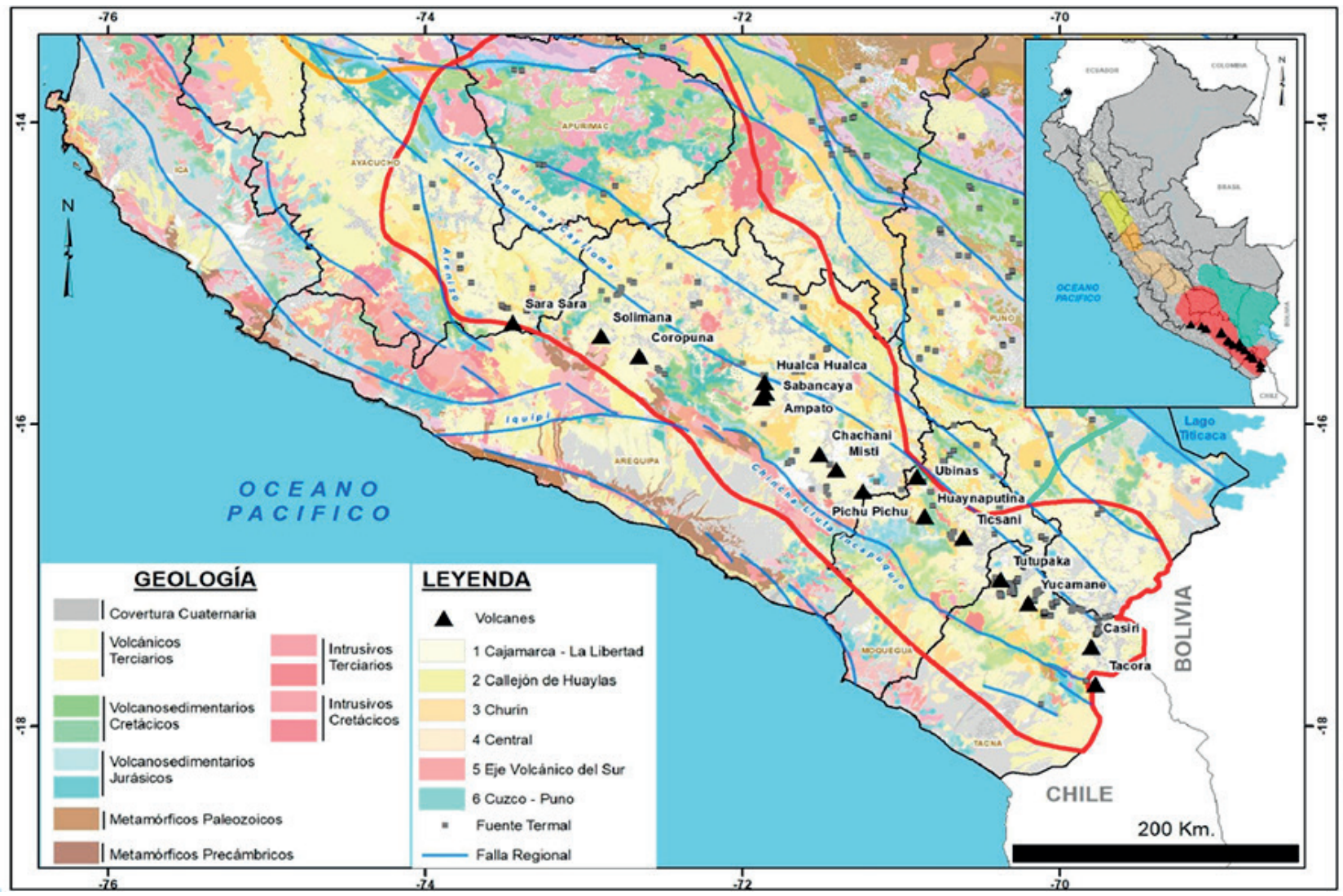

Figura 2. Mapa de la quinta región geotermal, eje volcánico sur (Fuente: INGEMMET) 
o correlacionados con las formaciones mencionadas, pero en realidad corresponden a diferentes eventos ocurridos en diferente tiempos geológicos asociados a la existencia de calderas, lo cual se apoya en las edades radiométricas (figura 3) efectuadas en algunos depósitos de rocas piroclásticas que demuestran que son de diferente edad y su origen está asociado a la existencia de calderas volcánicas y la mayoría de las aguas termales que afloran en un área determinada tienen relación con la evolución y formación de la caldera que ocurrió en tiempos geológicos diferentes.

Para identificar las calderas se ha recurrido al uso de las imágenes satelitales e interpretarlas y más la información geológica referida en (Wilson \& García, 1962); (Mendívil Echevarría, 1965); (Acosta et al., 2012); (Montoya Ramírez et al., 1994), se ha podido identificar dichas estructuras.

Previamente se delimitó en las imágenes satelitales los diferentes depósitos de tobas (figura 3) reportadas en los cuadrángulos geológicos publicados por INGEMMET: Geología de los cuadrángulos de la Yarada, Tacna y Huaylillas (Acosta et al., 2012); Geología de los cuadrángulos de Lomitas, Palpa, Nazca y Puquio (Montoya Ramírez et al., 1994) y otros boletines geológicos como el número 50, geología de los cuadrángulo de Chuquibamba y Cotahuasi (Olchauski Lomparte \& Dávila Manrique, 1994).

\section{RESULTADOS}

El análisis interpretativo de las imágenes de satélite ha permitido identificar lineamientos circulares que en la mayoría de los casos han sido aprovechados para el discurrimiento de agua formando ríos. El aspecto geomorfológico permite determinar relieves volcánicos en el que se puede observar alineamientos de volcanes que conforman parte la estructura circular, asimismo la presencia de domos resurgentes tanto en el borde circular de la caldera o al interior de la caldera que es el caso de la caldera Maure, también se puede apreciar la presencia de aguas termales de alta temperatura a lo largo del río Maure que cruza diagonalmente el borde NNE , de la caldera como el agua termal de Calachaca que tiene una temperatura de $90^{\circ} \mathrm{C}$., al interior de la caldera se tiene el domo Casiri y próximo a él se tiene una fuente termal con un temperatura de $80{ }^{\circ} \mathrm{C}$, lo cual indica que existe en profundidad una cámara magmática que calienta los reservorios de aguas subterráneas, formados por la infiltración de las aguas proveniente de las lluvias que ocurren y ocurrió hace muchos años en diferentes tiempos geológicos.

En la caldera de Coracora (Díaz Huaina, 2012) se puede apreciar como los afloramientos de aguas termales se

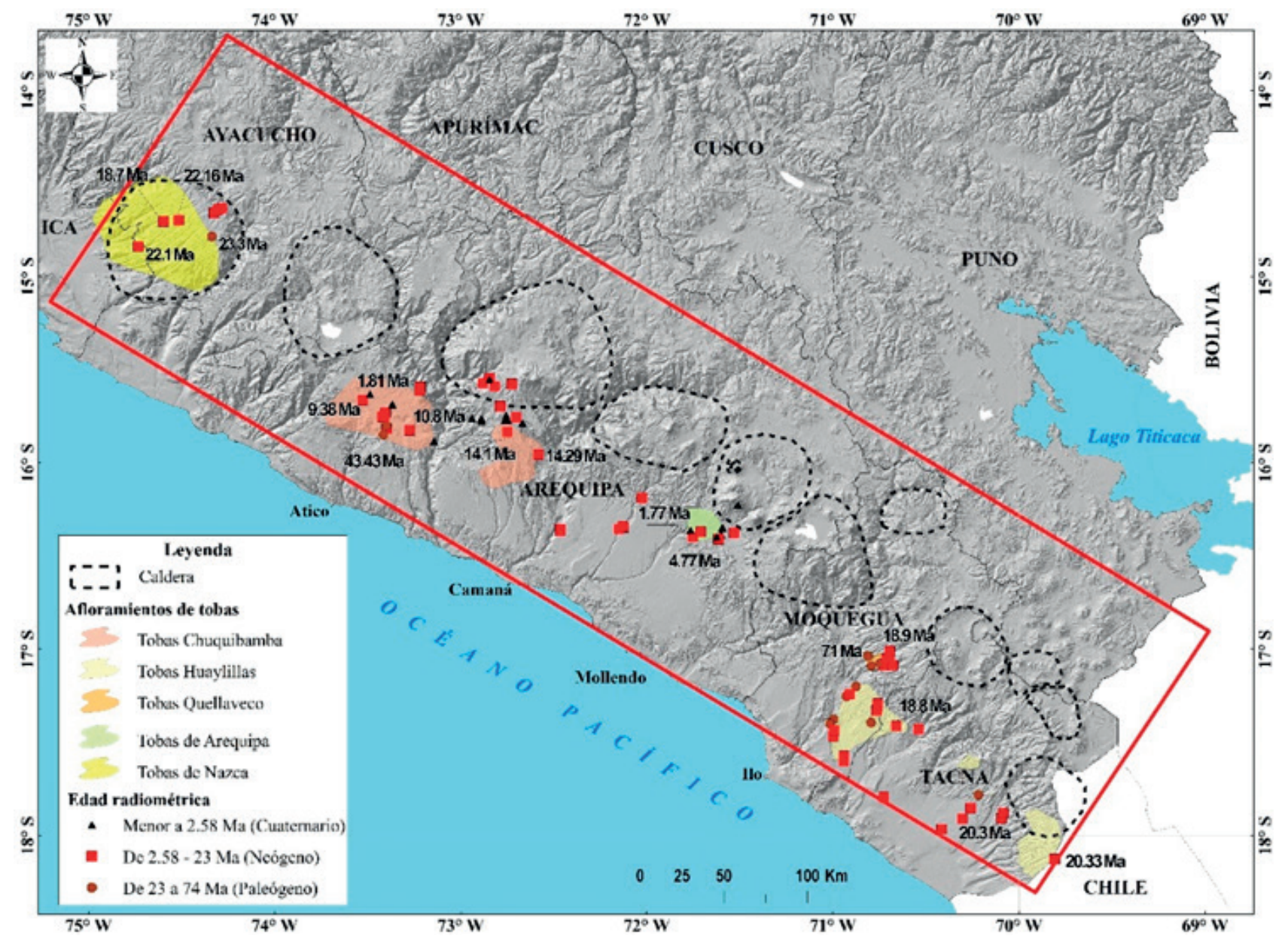

Figura 3. Delimitación de depósitos piroclásticos y dataciones radiométricas (tobas) 
alinean en parte a la estructura circular de la caldera lo que se puede interpretar de la existencia en profundidad de un reservorio de agua de alta entalpía que podría ser explotado con fines energéticos (figura 4).

Asimismo, se puede apreciar en la imagen otras estructuras caldéricas identificadas, donde se han ploteado las aguas termales y se distribuyen, tanto al interior y en el margen periférico de la caldera y son fuentes termales que tienen su presencia en cada lugar más de 80 años, lo cual indica la presencia de una cámara magmática activa que emite calor que es trasmitida a las aguas subterráneas generando la existencia de un yacimiento geotérmico, a ser evaluado.

\section{DISCUSION}

En el presente artículo se plantea una nueva metodología para la exploración en la búsqueda de un yacimiento geotérmico mediante la identificación de estructuras volcánicas denominadas calderas.

En la actualidad, el estudio de las calderas volcánicas está más asociada a la búsqueda de yacimientos epitermales, pero también puede ser dirigido a la búsqueda de yacimientos geotérmicos porque se ha establecido que varias manifestaciones de aguas termales de alta temperatura $90{ }^{\circ} \mathrm{C}-100^{\circ} \mathrm{C}$., se alinean a estructuras circulares como se puede apreciar en la caldera de Coracora.

Por consiguiente, se ha interpretado estructuras circulares que en parte de disponen volcanes en forma circular y lineamientos circulares entrecortados que al correlacionarlos definen una estructura circular, que se conoce con el nombre de caldera volcánica o calderas de colapso porque la parte interna generalmente está hundida debido al vaciado parcial de la cámara magmática, por consiguiente pone de manifiesto una fuente de calor proveniente de estas cámaras que trasmiten el calor a las subterráneas definiendo un reservorio geotérmico a ser evaluado con fines de generación eléctrica, que para el caso del Perú especialmente la zona sur cubriría la demanda de energía a largo y corto plazo.

La explotación de este tipo de yacimientos energéticos son energías limpias que no contamina el medio ambiente y son renovables, porque hoy en día el agua caliente que se extrae previa separación del vapor del agua, siendo el vapor el que mueve las turbinas y el agua restante es introducida al interior por un pozo de reinyección al reservorio en profundidad, constituyendo una energía renovable.

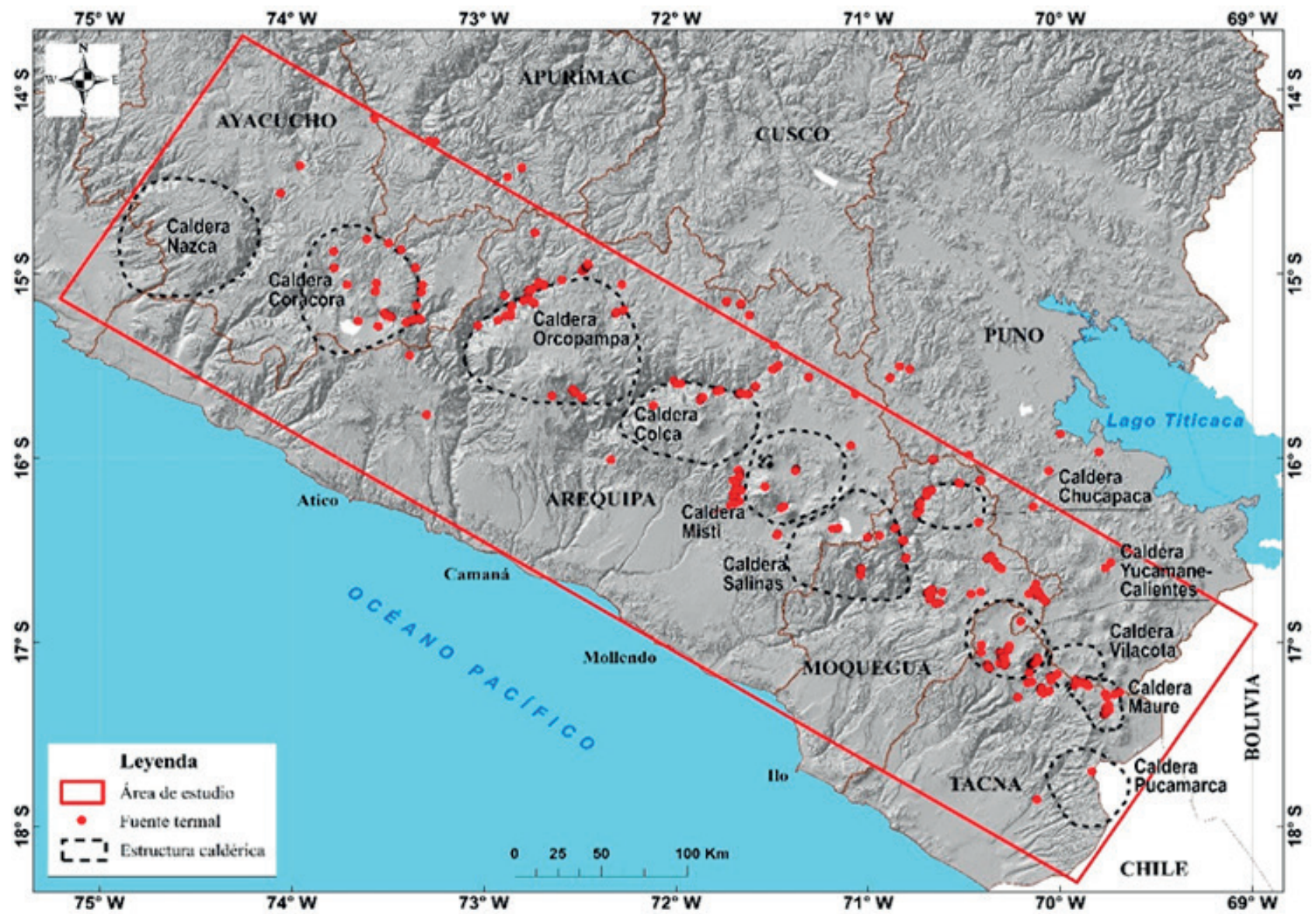

Figura 4. Delimitación de calderas volcánicas y fuentes termales 


\section{CONCLUSIONES}

\subsection{Conclusiones}

El Perú especialmente la región Sur por su relación con la tectónica de placas y el vulcanismo presente en la Cordillera Occidental y parte de la intra cordillera, está relacionado a la evolución y formación de estructuras caldéricas que explicarían la presencia de extensos depósitos de rocas piroclásticas, denominadas en la Carta Geológica Nacional por (Wilson \& García, 1962) y por (Mendívil Echevarría, 1965) bajo los nombres como Volcánico Huaylillas, Volcánico Sencca respectivamente.

Estas estructuras caldéricas pueden estar relacionado a la existencia de yacimientos geotérmicos en profundidad, por la siguiente razón de tener aguas termales de alta temperatura que afloran en superficie.

La existencia de domos resurgentes de edad muy joven como los domos Purupuruni presentes en la caldera de Maure que registra una edad con el método K-Ar de 0.1 $\mathrm{Ma}$, esto indica que tiene cámaras en profundidad todavía activas (Zegarra Figueroa, 2015).

\subsection{Recomendaciones}

- La exploración de recursos geotermales no solo se debe basarse en la presencia puntual de aguas termales en superficie, se debe analizar el entorno Geovulcanológico y establecer su relación de los depósitos piroclásticos, a la existencia de calderas volcánicas, establecer su evolución en el tiempo en función de la identificación de los productos volcánicos que afloran y estén asociados a la caldera, como los depósitos piroclásticos (tobas), domos volcánicos, aguas termales, depósitos de sínter, géiseres que atestiguan la existencia de una cámara magmática que calienta reservorios de aguas subterráneas.

- Existen áreas donde se tienen extensos depósitos de rocas piroclásticas que enmascaran las estructuras caldéricas es decir tenemos calderas ciegas, se tiene que revisar con sumo cuidado buscando evidencias como depósitos de sínter, conductos de feeder que evidencien actividad magmática en profundidad.

\section{AGRADECIMIENTOS}

Mi especial reconocimiento al Vicerrectorado de Investigación, el Consejo Superior de Investigación y el Instituto de Investigación de la Facultad de Ingeniería Geológica, Minera, Metalúrgica, Geográfica y Civil, de la Universidad Nacional Mayor de San Marcos, por el apoyo brindado en la publicación el presente artículo relacionado a la investigación científica en la Exploración de Recursos Geotérmicos a ser explotados con fines de generación eléctrica.

Al señor doctor Ing. Carlos Francisco Cabrera Carranza, decano de nuestra facultad, por las facilidades incondicionales para hacer realidad esta investigación científico-tecnológica y su publicación. También mi agradecimiento al $\mathrm{Mg}$ Enrique Guadalupe por sus sugerencias y al doctor Ing. Javier Jacay Huachare revisor oficial del Instituto de investigación por sus sugerencias al presente artículo.

\section{REFERENCIAS}

Acosta, H., Alvan de la Cruz, A., Mamani, M., Rodrìguez, J., \& Cutipa, M. (2012). Geología de los cuadrángulos de la Yarada, Tacna y Huaylillas, hojas $37 \mathrm{u}, 37 \mathrm{v}$ y $37 \mathrm{x}$. In INGEMMET (Vol. 1). https://repositorio.ingemmet.gob.pe/ handle/20.500.12544/107

Díaz Huaina, G. (2012). Evolución volcano tectónica de la caldera de Coracora y su relación con zonas mineralizadas. Sociedad Geológica Del Perú. http:// catalogobiblioteca.ingemmet.gob.pe/cgi-bin/koha/ opac-detail.pl?biblionumber $=12146 \&$ shelfbrowse itemnumber $=12146 \#$ holdings

Gregg, P. M., De Silva, S. L., Grosfils, E. B., \& Parmigiani, J. P. (2012). Catastrophic caldera-forming eruptions: Thermomechanics and implications for eruption triggering and maximum caldera dimensions on Earth. Journal of Volcanology and Geothermal Research, 241-242, 1-12. https://doi.org/10.1016/j.jvolgeores.2012.06.009

Guevara, C., \& Dávila, D. (1983). Estratigrafía Terciaria del área Coracora-Pacapausa. Sociedad Geológica Del Perú. https://www.sgp.org.pe/category/bibliovirtual/?result=4165

Jenks, W. F. (1948). Geology of the Arequipa quadrangle. Boln. Inst. Geol., Peru, 9, 204. https://repositorio.ingemmet.gob. pe/handle/20.500.12544/2807

Lipman, P. W. (2000). Encyclopedia of volcanoes. In Encyclopedia of volcanoes. https://doi.org/10.1063/1.1325206

Mendívil Echevarría, S. (1965). Geología de los cuadrángulos de Maure y Antajave (Hojas 35-x, 35-y) - [Boletín A 10]. INGEMMET. https://repositorio.ingemmet.gob.pe/ handle/20.500.12544/180

Montoya Ramírez, M. A., García Márquez, W., \& Caldas Vidal, J. (1994). Geologia de los cuadrángulos de Lomitas, Palpa, Nasca y Puquio 30-1, 30-m, 30-n, 30-ñ [Boletín A 53]. Ingemmet. https://repositorio.ingemmet.gob.pe/ handle/20.500.12544/174

Noble, D. C., Farrar, E., \& Cobbing, E. J. (1979). The Nazca Group of south-central Peru: Age, source, and regional volcanic and tectonic significance. Earth and Planetary Science Letters, 45(1), 80-86. https://doi.org/10.1016/0012$821 X(79) 90109-2$

Olchauski Lomparte, E., \& Dávila Manrique, D. (1994). Geología de los cuadrángulos de Chuquibamba y Cotahuasi 32-q, 31-q - [Boletín A 50]. In INGEMMET. https://repositorio. ingemmet.gob.pe/handle/20.500.12544/171

Wilson, J., \& García, W. (1962). Geología de los cuadrángulos de Pachía y Palca (Hojas 36-v y 36-x) - [Boletín A 4]. In INGEMMET. https://repositorio.ingemmet.gob.pe/ handle/20.500.12544/114

Zegarra Figueroa, F. (2015). Exploracion de energia geotermica y avances para su desarrollo en el Perú. In Recursos Minerales y Energéticos - INGEMMET. https://www.sgp.org.pe/wpcontent/uploads/MG-23.09.15-Francisco-Zegarra-expo.pdf 